\title{
Energetic Particle Precipitation during Extreme Space Weather Events
}

\author{
Olesya Yakovchuk $^{1,2,3}$ and Irina Mironova ${ }^{1, *}$ \\ ${ }^{1}$ Department of Physics of Earth, Faculty of Physics, Saint Petersburg State University, \\ Saint Petersburg, Russia \\ ${ }^{2}$ Institute for Environmental Systems Research, University of Osnabrück, \\ Osnabrück, Germany \\ ${ }^{3}$ Skobeltsyn Institute of Nuclear Physics, Moscow State University, Moscow, Russia
}

\begin{abstract}
Here we provide a selection of extreme geomagnetic storms of the last century based on NOAA classification which lead to the energetic particle precipitation (EPP). EPP of such geomagnetic storms can cause power outages, communication failures, and navigation problems as well as impact on the environment and the ozone level. Studies of historical extreme geomagnetic storms together with EPP for large space weather events in the space era can help to reconstruct the parameters of extreme events of past centuries.
\end{abstract}

\section{Introduction}

The study of solar-terrestrial relations, especially during extreme disturbances are always topical and important both from the scientific and practical points of view due to the increased awareness of the versatile effects of the Sun on the near-Earth space environment, atmosphere and climate, upon the many technological systems [1]. The study of the causes and effects of solar-related disturbances is nowadays known under the name "space weather" $[2,3]$.

The first extreme space weather event was observed, among others, by Richard Carrington on September 1, 1859, as a flare in the white light [4]. Soon thereafter (in 17 hours 40 minutes) serious disruptions of the wired telegraph were noted in America and Europe during several hours and auroras were observed in Rome, Havana, Bahamas, Jamaica and Hawaii. The Carrington event has remained a subject of active studies for more than 150 years [e.g. 1, 4-9].

The scales of space weather events were developed by National Oceanic and Atmospheric Administration Space Weather Prediction Center (NOAA SWPC) in an effort to better quantify space weather [3]. These scales serve as a sort of Richter scale that, e.g., correlates space weather events with their probable consequences such as effects on technological systems. The conditions of the near-Earth space environment according the NOAA classification are estimated using five levels of space weather disturbance: minor (1), moderate (2), strong (3), severe (4), and extreme (5).

\footnotetext{
* Corresponding author: i.a.mironova@spbu.ru
} 
The levels are defined for three types of parameters: radio blackouts or solar X-ray events (R1-R5), solar proton events (S1-S5) and geomagnetic storms (G1-G5) (see Table 1). The five X-ray classes (R1-R5) are defined by the maximum intensity of electromagnetic radiation during an event, measured at the Earth's orbit in the range of soft $\mathrm{X}$-rays $1-12.5 \mathrm{keV}(0.1-0.8 \mathrm{~nm})$. The intensity of X-ray flux is measured in watts per square meter $\left(\mathrm{Wm}^{-2}\right)$. X-ray flares can lead to sudden ionospheric disturbances and to the breaking of radio communication of up to several hours.

Table 1. NOAA classification of space weather perturbations.

\begin{tabular}{|l|l|l|l|}
\hline NOAA scale & $\begin{array}{l}\text { R radio blackouts } \\
\text { (X-ray flux) }\end{array}$ & $\begin{array}{l}\text { S SEP } \\
\text { (flux of E }>10 \mathrm{MeV} \\
\text { particles })\end{array}$ & $\begin{array}{l}\text { G geomagnetic storm } \\
\text { (Kp value) }\end{array}$ \\
\hline $5-$ Extreme & $>\mathrm{X} 20\left(2 \times 10^{-3} \mathrm{~W} \mathrm{~m}^{-2}\right)$ & $>100,000 \mathrm{pfu}$ & 9 \\
\hline $4-$ Severe & $>\mathrm{X} 10\left(10^{-3} \mathrm{~W} \mathrm{~m}^{-2}\right)$ & $>10,000 \mathrm{pfu}$ & 8 and 9- \\
\hline $3-$ Strong & $>\mathrm{X} 1\left(10^{-4} \mathrm{~W} \mathrm{~m}^{-2}\right)$ & $>1000 \mathrm{pfu}$ & 7 \\
\hline $2-$ Moderate & $>\mathrm{M} 5\left(5 \times 10^{-5} \mathrm{~W} \mathrm{~m}^{-2}\right)$ & $>100 \mathrm{pfu}$ & 6 \\
\hline $1-$ Minor & $>\mathrm{M} 1\left(10^{-5} \mathrm{~W} \mathrm{~m}^{-2}\right)$ & $>10 \mathrm{pfu}$ & 5 \\
\hline
\end{tabular}

Solar proton event classification (S1-S5) is based on the measurement of the number of solar protons at the Earth's orbit. NOAA gives solar proton events in units of pfu (proton flux unit), which is the number of protons at the Earth's orbit per square centimeter per steradian per second with energy above $10 \mathrm{MeV}$. The high $\mathrm{S}$ level events can lead to the violation of radio communication and risk the health of astronauts. Aircraft passengers and crew at high latitudes may be exposed to radiation risk.

Geomagnetic storms (G1-G5) are perturbations of the geomagnetic field caused by solar plasma streams of increased density or velocity and, in particular, carrying a strong and persistent southward $\mathrm{Bz}$-component of the interplanetary magnetic field. Index $\mathrm{G}$ is determined by the values of the three-hourly geomagnetic Kp index: measurements of the magnetic field at 11 mid-latitude (between $44^{\circ}-60^{\circ}$ ) observatories. Levels G1-G5 correspond to maximum $\mathrm{Kp}$ index values from 5 to 9 . The database of $\mathrm{Kp}$ indices since 1932 is available in web [10]. Extreme geomagnetic storms can break power systems and spacecraft orientations for hours of even days, cause problems to GPS and other navigation systems, induced pipeline currents can reach hundreds of amps and aurora has been seen as low as Florida and southern Texas (typically $40^{\circ}$ geomagnetic latitude).

Extreme geoeffectiveness is very often defined in terms of the geomagnetic Dst index reaching $-250 \mathrm{nT}$ or lower $[11,12]$. The $\mathrm{Kp}$ and Dst indices are measured at different latitudes: mid-latitudes and low-latitudes respectively.

For our investigation we have chosen extreme geomagnetic storms based on $\mathrm{Kp}$ index for some reasons. The Kp index is sensitive to several current systems, while the Dst index is mainly due to the ring current. The Kp index is available 25 years longer, then Dst. Apart from that most models that describe particle precipitation or the according ionization are based on Kp index [e.g. 11-15].

\section{Selected Extreme Geomagnetic Storms}

Table 2 presents all extreme geomagnetic storms (G5 level), according to NOAA scale, which corresponds to $\mathrm{Kp}=9$ for the whole period of availability of $\mathrm{Kp}$ index since 1932 . 
The columns in the table indicate: (1) number of event; (2) the year; (3) the date of geomagnetic storm; (4) the duration (in hours) of geomagnetic storm; (5) the date of the event on the Sun; (6) flare class [16]; (7) the solar energetic proton flux (in pfu) [17-19]; (8) the maximum Ap index [10]; (9) the minimum Dst index [20]; the related five-scale NOAA classes for (10) R and (11) S, when their classification is available.

Table 2. The database of the extreme geomagnetic storms and their characteristics during the last century.

\begin{tabular}{|l|l|l|l|l|l|l|l|l|l|l|}
\hline $\mathbf{N}$ & Year & $\begin{array}{l}\text { Storm } \\
\text { duration, } \\
\text { date }\end{array}$ & $\begin{array}{l}\text { Hou } \\
\text { rs }\end{array}$ & $\begin{array}{l}\text { Date } \\
\text { on the } \\
\text { Sun }\end{array}$ & Flare class & SEP & Ap & Dst & R & S \\
\hline 1 & 1940 & $23-27.03$ & 78 & 23.03 & 3 & & 277 & & & \\
\hline 2 & 1941 & $04-08.07$ & 69 & 03.07 & $3+$ & & 222 & & & \\
\hline 3 & 1946 & $25-28.07$ & 36 & 25.07 & $3+$ & & 212 & & & \\
\hline 4 & 1946 & $21-24.09$ & 63 & 19.09 & 3 & & 214 & & & \\
\hline 5 & 1957 & $01-06.09$ & 105 & 31.08 & 3 & & 221 & -324 & & \\
\hline 6 & 1958 & $07-10.07$ & 48 & 07.07 & $3+$ & & 216 & -330 & & \\
\hline 7 & 1959 & $15-17.07$ & 42 & 14.07 & $3+$ & 240 & 252 & -429 & & 4 \\
\hline 8 & 1960 & $12-16.11$ & 54 & 12.11 & $3+$ & 21000 & 293 & -339 & & 4 \\
\hline 9 & 1967 & $24-27.05$ & 45 & 23.05 & $3 B$ & & 241 & -387 & & \\
\hline 10 & 1972 & $03-07.08$ & 81 & 04.08 & $X>5 / 3 B$ & 86000 & 223 & -125 & 5 & 4 \\
\hline 11 & 1972 & $8-10.08$ & 27 & 07.08 & $X>5,4 />30$ & 3500 & 111 & -154 & 5 & 3 \\
\hline 12 & 1982 & $11-15.07$ & 78 & 09.07 & $X 9 / 3 B, X 7.1$ & 2900 & 229 & -325 & 4 & 3 \\
\hline 13 & 1986 & $6-10.02$ & 63 & 06.02 & $X 1 / 3 B$ & 130 & 228 & -307 & 3 & 2 \\
\hline 14 & 1989 & $12-16.03$ & 69 & 10.03 & $X 4$ & 3500 & 285 & -589 & 3 & 3 \\
\hline 15 & 2000 & $13-17.05$ & 54 & 14.07 & $X 5 / 3 B$ & 24000 & 192 & -301 & 3 & 4 \\
\hline 16 & 2003 & $29.10-01.11$ & 78 & 28.10 & $\begin{array}{l}X 17.2 / 4 B \\
X 10 / 2 B\end{array}$ & 29500 & 252 & -383 & 5 & 4 \\
& & & & 29.10 & $X 10 / 2$ & & & & \\
\hline
\end{tabular}

The list of selected geomagnetic events is very short, but the extreme events are rare by definition. All these events have duration more than 2 days in average. It is worth to note, that according to NOAA classification there were no extreme geomagnetic event during the last 17 years (one and half solar cycle). This situation occurred for the first time during the last century. If the lower threshold of the $\mathrm{G} 4$ level $(\mathrm{Kp}=8)$ is applied, the statistic of strong and extreme geomagnetic event will rise to more than 50 [21].

\section{Energetic Particle Precipitation during selected Extreme Geomagnetic Storms}

Each extreme geomagnetic storm leads to energetic particle precipitation (EPP). EPP mostly contains electrons and protons and depends on the energy and intensity of the precipitating flux. EPP leads to increased atmospheric ionization rates [21-27]. Solar energetic protons precipitate mostly into the middle mesosphere and down to the stratosphere, electrons affect the lower thermosphere to the upper mesosphere. Both solar proton and energetic electron precipitation have a long-lasting impact on the atmospheric composition and e.g. ozone during polar winter [e.g. 27-29]. While ozone plays a key role 
in radiative heating and cooling of the stratosphere, changes in its concentration induce dynamical changes in the middle atmosphere, which couple down to the troposphere and affect regional climate. Usually, each extreme geomagnetic storm is separately investigated from an atmospheric point of view [e.g. 30-32].

In Table 2 it is seen that extreme geomagnetic storms are followed up by solar EPP that includes mostly protons as well as enhanced magnetospheric electron precipitation during the whole duration of the geomagnetic storm.
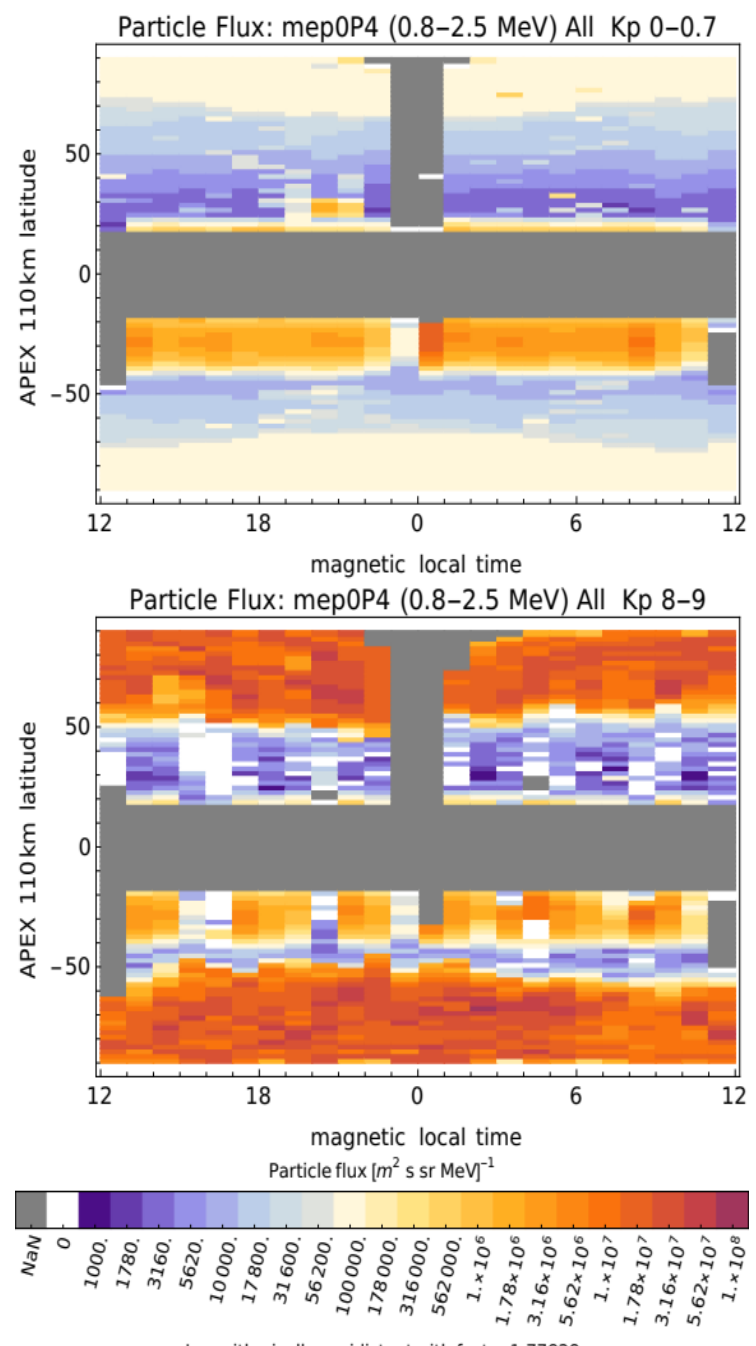

Logarithmically equidistant with factor 1.77828

Fig.1. Particle flux in mep0P4 proton channel with energy $0.8-2.5 \mathrm{MeV}$ in modified APEX $110 \mathrm{~km}$ coordinates for the quiet geomagnetic period $\mathrm{Kp}=0-0.7$ (top) and extreme disturbance (Kp=8-9) (bottom). 
As an example we present two average precipitation maps for a quiet $(\mathrm{Kp}=0-0.7)$ and severe-extreme $(\mathrm{Kp}=8-9)$ period in magnetic local time and magnetic coordinates (modified APEX $100 \mathrm{~km}$ [33]). These coordinates map the particles down to $110 \mathrm{~km}$ altitude, where the atmospheric ionisation takes place (see Fig. 1). The detailed description of the precipitation maps in magnetic coordinate system (modified APEX) and MLT destribution can be found in [27]. For particle data we use time series (2001-2018) of 16s averaged protons from 0.8 to $2.5 \mathrm{MeV}$ measured on board the polar orbiting NOAA/POES and their successor, the METOP satellites [34].

In the period 2001-2018 just one extreme $(\mathrm{Kp}=9)$ event occured, the so called October Halloween Event of 2003. However, that event alone does not provide a good spatial coverage. For that reason we added all $(15)$ severe $(\mathrm{Kp}=8)$ events, which took place in 2001-2018 for a better coverage statistics. During the quiet period (top) just minimal particle precipitation takes place in the polar cap around $73^{\circ}-75^{\circ}$ latitude range. The precipitation map for extreme events shows a shift towards the equator by $25^{\circ}$ and reaches at maximum $45^{\circ}$ geomagnetic latitude. This picture supports the fact that the extreme space wheather events initiate the aurora at low latitudes.

\section{Conclusion}

Here we provide a collection of all extreme geomagnetic storms $(\mathrm{Kp}=9)$ during the last century based on NOAA classification. We document that there are no extreme geomagnetic events during the last 17 years (from November 2003 till October 2020). We calculated the mean EPP that followed on geomagnetic storms with $\mathrm{Kp}=8-9$. The location of this EPP links it to aurora at low latitudes.

This small collection is a first step in the study of extreme geomagnetic storms, EPP and its atmospherical application. Reconstructed geomagnetic storm parameters will help to study extreme space weather events and their EPP with possible extrapolation of these events to extreme geomagnetic events in the past.

\section{Acknowledgments}

The study was supported by the grant Russian Science Foundation (RSF project No. 20-67-46016).

O. Yakovchuk also thanks support from German Science Foundation (DFG project WI4417/2-1).

\section{References}

1. Extreme Events in Geospace: Origins, Predictability, and Consequences, Ed. Natalia Buzulukova, (Elsevier, 798, 2018)

2. Schwenn, R. Living Reviews in Solar Physics, 3 , 2 (2006)

3. NOAA, Space Weather Scales, in the WWW at https://www.swpc.noaa.gov/noaascales-explanation by National Oceanic and Atmospheric Administration (NOAA) Space Weather Prediction Center (SWPC), Washington, USA (2020)

4. Carrington, R. C., Esq., Monthly Notices of the Royal Astronomical Society, 20(1), 13-15 (1859) 
5. Chapman, S., and J. Bartels, Geomagnetism ( Oxford University Press, New York, U.S.A. 1940)

6. Tsurutani, B. T., W. D. Gonzalez, G. S. Lakhina, S. Alex, , J. Geophys. Res., 108, $1268(2003)$

7. Tyasto, M. I., N. G. Ptitsyna, I. S. Veselovsky, and O. S. Yakovchouk, Geomagnetism and Aeronomy/Geomagnetizm i Aeronomiia, 49 , 153-162 (2009)

8. Yakovchouk, O.S., I.S. Veselovsky, K. Mursula, Advances in Space Research, 43, (4), 634-640 (2009)

9. Wolff, E. W., M. Bigler, M. A. J. Curran, J. E. Dibb, et al., Geophys. Res. Lett., $39,8503(2012)$

10. GFZ, Kp station list by the Germany's National Research Centre for Geosciences, in the WWW (https://www.gfz-potsdam.de/en/kp-index/), GeoForschungsZentrum (GFZ), Potsdam, Germany,(2020)

11. Gonzalez, W.D., B.T. Tsurutani, R.P. Lepping \& R. Schwenn, JASTP, 64(2), 173-181 (2002)

12. Meng, X., B.T. Tsurutani, A.J Mannucci, J. Geophys. Res., 124(6), 3926-3948 (2019)

13. Hardy, D. A., M. S.Gussenhoven, E. Holeman, J. Geophys. Res. 90, 4229-4248 (1985)

14. Zhang, Y. ; Paxton, L.J. JASTP, 70(8), 1231124 (2008)

15. Wissing, J. M., M-B. Kallenrode, J. Geophys. Res., 114 A6 (2009)

16. NGDC,_Solar flares data base, via anonymous FTP (https://www.ngdc.noaa.gov/stp/solar/solarflares.html) from the National Geophysical Data Center (NGDC), Boulder, Colorado, USA (2020)

17. SWPC, Solar Proton Events affecting the Earth environment, available via anonymous FTP server (https://umbra.nascom.nasa.gov/SEP/) from the Space Weather Prediction Center (SWPC) of the National Oceanic and Atmospheric Administration (NOAA), Boulder, USA (2020)

18. Shea, M. A., and D. F. Smart, Sol. Phys., 127, 297-320, (1990)

19. Logachev, Yu, G. Bazilevskaya, E. Vashenyuk, E. Daibog, et al. Catalog of Solar Proton Events in the 23rd Cycle of Solar Activity (1996-2008), Geophysical Center of the Russian Academy of Sciences Moscow, Russia, 740 (2016)

20. WDC, World Data Center for Geomagnetism, Kyoto, M. Nose, T. Iyemori, M. Sugiura, T. Kamei, Geomagnetic Dst index, (2015)

21. Yakovchuk, O.S. and J.M. Wissing, Annales Geophysicae, 7(6), 1063-1077 (2019)

22. Mironova, I. A., K. L. Aplin, , F. Arnold, G.A. Bazilevskaya, R.G. Harrison, A.A. Krivolutsky, et al. Space Science Reviews, 194, 1-96, (2015)

23. Wissing, J. M., M.B. Kallenrode, N. Wieters, H. Winkler, and M. Sinnhuber, J. Geophys. Res., 115, A02308 (2010)

24. Artamonov, A., I. Mironova, G. Kovaltsov, A. Mishev, et al., Advances in Space Research, 59(9), 2295-2300 (2017)

25. Mironova, I. A., A. A. Artamonov, G. A. Bazilevskaya, E. V. Rozanov, et al., Geophys. Res. Lett., 46(2), 990-996 (2019)

26. Mironova, I., G. Bazilevskaya, G. Kovaltsov, A. Artamonov, E. Rozanov, et al., Sci. Total Environ. 693, 133242 (2019)

27. Matthes, K., B. Funke, M. E. Andersson, L. Barnard, J Beer, P Charbonneau, P. et al., Geos Model Development, 10, 2247-2302 (2017)

28. Rozanov, E., M. Calisto, T. Egorova, T. Peter \& W. Schmutz, Surveys in Geophysics, 33, 483-501 (2012)

29. Sinnhuber, M. , H. Nieder, N. Wieters, Surv. Geophys. 33, 1281-1334 (2012) 
30. López Puertas, M., B. Funke, S. Gil López, T. von Clarmann, et al., J. Geophys. Res., 110, A09S43 (2005)

31. Funke, B, A. Baumgaertner, M. Calisto, T. Egorova, et al. Atmos. Chem. Phys. 11, 9089-9139 (2011)

32. Mironova, I. A. and I.G. Usoskin, Atmos. Chem. Phys., 13, 8543-8550 (2013)

33. Richmond, A. D.: Journal of Geomagnetism and Geoelectricity, 47, 191-212 (1995)

34. Evans, D. S. and M.S. Polar Orbiting Environmental Satellite Space Environment Monitor - 2, Instrument Descriptions and Archive Data Documentation (NOAA Space Environ. Lab, Boulder, Colorado, USA, version 2.0, 2006) 